University of South Carolina

Scholar Commons

$11-1979$

\title{
A Hypothesis for the Use of Cryptocrystalline Raw Materials Among Paleo-Indian Groups of North America
}

Albert C. Goodyear

University of South Carolina - Columbia, goodyear@mailbox.sc.edu

Follow this and additional works at: https://scholarcommons.sc.edu/archanth_books

Part of the Anthropology Commons

\section{Recommended Citation}

Goodyear, Albert C., "A Hypothesis for the Use of Cryptocrystalline Raw Materials Among Paleo-Indian Groups of North America" (1979). Research Manuscript Series. 127.

https://scholarcommons.sc.edu/archanth_books/127

This Book is brought to you by the Archaeology and Anthropology, South Carolina Institute of at Scholar Commons. It has been accepted for inclusion in Research Manuscript Series by an authorized administrator of Scholar Commons. For more information, please contact digres@mailbox.sc.edu. 


\section{A Hypothesis for the Use of Cryptocrystalline Raw Materials Among Paleo-Indian Groups of North America}

\section{Keywords}

Excavations, Indians of North America, Stone implements, South Carolina, Archeology

Disciplines

Anthropology

Publisher

The South Carolina Institute of Archeology and Anthropology--University of South Carolina

Comments

In USC online Library catalog at: http://www.sc.edu/library/ 
A HYTOTHESIS FOR THE USE' OR CRYPTOCRYSTALI, I NH WH

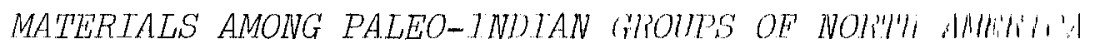

by

Albert C. Goodyear

Research Manuscript ieries No. liti

The University of South Carolina offers equal opportullly 11111 a sinflingmont.

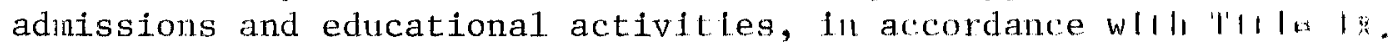
sestion 504 of the Rehabilitation Act of 1973 and other 1.1411 11phe laws.

Prepared by the INSTITUTE OF ARCHLOLOGY ANI ANTHROPOH,QH:Y

UNTVERSTTY OF' SOUI'II CARROLINA

November, 1979 


\section{Introduction}

The widespread existence of distinctive Paleo-Indian chipped stone technologies has been recognized in North American archeology for decades. Great attention has been paid to the striking homogeneity of tool forms within these technologies over time and space and the high standards of craftsmanship involved in the production of the characteristic bifacial and unifacial tools. Equally impressive as the emphasis on consistency in tool forms, however, is the remarkable uniformity in the selection of cryptocrystalline and microcrystalline siliceous rocks as a raw material base for tool manufacture. This archeological regularity is readily observable over all of North America wherever Paleo-Indian assemblages are found, a regularity that was maintained in some areas for nearly 4,000 years. This heavy reliance on cryptocrystalline lithic material is not without adaptive significance and requires explanation as a significant feature of the Paleo-Indian archeological record like any other assemblage property. The adaptive value of fine-grained siliceous raw materials is an integral part of the Paleo-Indian lithic tool kit based on the special technological needs of a geographically mobile settlement system.

\section{The Problem}

The intensive focus on fine-grained siliceous raw materials among such Paleo-Indian complexes as Clovis (or Llano), Folsom, fluted and early lanceolate point complexes of the East, and the various Plano manifestations of the Plains, has been noted in varying degrees by Paleo-Indian specialists in their attempts to summarize Early Man in North America (Wormington 1957; Wilmsen 1970; MacDonald 1971). Other grand culture-historical syntheses, however, ignore the raw material 
aspect altogether (Krieger 1964; Willey 1966; Jennings 1974). Frequently, archeologists will draw attention to the presence of distinctive high quality raw materials over an area by bestowing names. A few, among the many of these drawn throughout North America, include Knife River flint, Alibates flint, Pennsylvania jasper, Flint Ridge, Bayport chert, Normanskil1 flint, Onondaga flint and several others. Until recently, minimal analytical attention had been given to analyzing the significance of high quality lithic remains beyond describing their presence on a site description basis and noting the presence of what appear to be exotic lithic materials. Lately, some beginnings have been made in analyzing the areal distributions of exotic materials in an effort to reconstruct movement patterns (Ritchie 1969; Funk 1972) and band territory sizes (Hester and Grady 1977). Perhaps the most ambitious theoretical use of the cryptocrystalline pattern is that by Gardner (1977) who, in recognition of the strong focus on such materials by Paleo-Indian groups in the East, has argued that their settlement pattern and geographical movements were limited by a strict dependence on these materials.

Cryptocrystalline Raw Materials, Paleo-Indian Technologies and Mobile Settlement Systems

The idea of widespread geographic movement among Paleo-Indian populations in the New World has been a commonly accepted idea for some time in American archeology (Beardsley et al. 1956: 135-137). Although differences in opinion exist regarding the extent of movement and the reasons behind such mobility, most archeologists seem to agree that, due to low population densities and the existence of vast areas of unoccupied landscape during the late Pleistocene, Paleo-Indian manifestations reflect a wide geographic dispersion of human populations. The issue I 
wish to discuss here concerns the relationship between groups of huntergatherers, regardless of their existence in time and space, who routinely move their settlements several miles a year, and the character of their technology. Specifically, what special technologies would be adaptive in a lifeway characterized by high mobility?

If movement over an area is predicated first and foremost on the relative abundance of biotic resources in their spatial and seasonal contexts of availability, it is likely that some severe spatial incongruences will occur between the natural locations of rocks suitable for making stone tools and the loci where such tools are to be used in extractive and processing activities. It is a general geological fact in most places of North America and probably throughout the world that lithic raw materials of even minimal suitability for flaking do not occur evenly over the earth's surface. In fact, some environments such as coastal plains and alluvial valleys have no lithic raw materials whatsoever. Although geographically discrete in distribution, the occurrence of lithic raw material is a stable therefore predictable phenomenon. This contrasts with the location and availability of many biotic resources, especially animals, (see Yellen 1977: 30-35) which are much harder to predict. Although there might be suitable raw material of some type (not just cryptocrystalline) in the immediate vicinity of a resource encounter, such as a kill, the search time involved and the strong likelihood of failure to find raw material would insure the efficiency of carrying technologies.

Thus, the first major problem posed by adaptations effected through wide ranging movement is a logistical one, i.e., getting the necessary technologies together with the locations of required subsistence functions 
(see Binford 1978: 458-459). This problem is essentially solved through the creation of portable technologies (see Schiffer 1975: 269).

A second major problem posed by a highly mobile lifeway can be subsumed under the rubric "situational contingencies" (cf. Binford 1978: 454; n.d.). This problem is akin to the first in that much variation is introduced into the adaptation on a daily basis as a result of the varying physical conditions under which activities occur. In order to maximize resource encounter situations, great value is placed on being flexibility. Another major constraint as well as source of variation in the situational response is the condition of the chipped stone tool kit from pose to pose. If the problem of geographic incongruences can be solved through portable technologies, the problem of situational contingencies can be alleviated through flexible technologies. Flexibility means creating tools with lifespans long enough to be used on a number of occasions if necessary. With chipped stone tools this means designing tools which can be continuously and reliably rejuvenated. Flexibility also means the capability for redesigning tools as other tools and otherwise re-casting the raw material of the tool kit into wholly new tools or cores for the derivation of tools if necessary. If we place such requirements for flexibility as just defined within the additional and prior stricture of portability, I believe the form and variable condition of North American Paleo-Indian technologies become potentially more understandable.

How, therefore, does the use of cryptocrystalline raw material aid in solving the adaptive problems posed by mobile settlement systems? First, the use of fine-grained materials allows a flint knapper to construct cores and tools with the highest degree of control over the 
reduction process. Lithic tool manufacture is a uni-directional reductive process such that errors in mass removal at one stage can have disastrous consequences for tool design at subsequent stages. Where precise removal is desired for tool manufacture, maintenance, or recycling, cryptocrystalline raw materials provide the greatest control, particularly since they can be pressure flaked. Second, for tools and cores that must be maintained for extending lifespan and providing cores or blanks for the production of other tools, a premium is placed on isotrop/lic materials that can be reliably flaked with minimal breakage. Such materials can be said to have a high degree of "plasticity" because they can be transformed from design to design with the greatest ease and success. While such factors as control, reliability, and "plasticity" in lithic reduction may have been of interest to some degree to any cultural system relying on chipped stone technologies, for highly mobile groups, these features are critical for the problem of tool acquisition, and tool replacement is undoubtedly more severe.

If the foregoing ideas have any validity for Paleo-Indian groups in North America, then at a minimum the following expectations should be met in their archeological records. First, there should be some demonstration of mobility among those widely varying groups archeologists call "PaleoIndian." If it can be shown that, in fact, such groups were not very mobile, then the adaptive advantage of cryptocrystalline raw materials would be significantly lessened. Second, evidence should exist that such materials are more easily controlled than coarser grained materials and that such flaking qualities do enable the production of tool forms and edges with greater precision and reliability. Third, there must be evidence that tools based on these raw materials were manipulated in 
such a way as to extend their use lives, and in some cases, were recycled or "liquidated" into entirely new forms.

Evidence of Mobility

Perhaps the only way to archeologically monitor mobility patterns among Paleo-Indian groups is to examine the geographic distributions of the distinctive raw materials they utilized. Here I am referring to tracing exotic raw material distributions from source points to locus of deposition. Such a strategy has been offered before in Early Man studies (Ritchie 1969; Witthoft 1952; Funk 1972; Hester and Grady 1977).

Several published sources pertaining to sites ranging from Nova Scotia to Colorado were consulted for statements about the presence of exotic raw materials and the distance to their presumed source locations. For fluted point sites in New York State, Ritchie (1969: 8-9) describes the regular appearance of Pennsylvania jasper from quarries in southeast Pennsylvania, distances ranging from 100 to 150 miles. At the Shoop site, Witthoft (1952: 470-473) states that quantities of Onondaga flint were found imported from western New York a distance of some 200 miles. Robert Funk (1972: 29), summarizing the widespread occurrence of exotic materials at the sites of Potts, West Athens Hill, Kings Road, Shoop, Davis, Bull Brook, Port Mobil, and Williamson, states, "In every case some materials had been carried to the sites from sources 30 to 100 or more miles distant."

At the Holcombe site in Michigan, Fitting et al. (1966: 126) indicate that all of the lithic material was imported. According to Fitting, $97 \%$ of the assemblage was Bayport chert which he believes was procured 100 miles north of the site. 
For the western sites, Wilmsen (1970: 27) states that all of the specimens at Blackwater Draw were imported; one-third of the assemblage was obtained from the Alibates quarry in Texas, located about 100 miles from the site. At the Lindenmeier site, Wilmsen and Roberts (1978: 114) report that a distinctive jasper was imported from outcrops that could be no closer in origin than 96 miles. At the Domebo site in southern Oklahoma, Leonhardy and Anderson (1966: 18) report that the chert artifacts associated with the mammoth appear most similar to tabular chert found in the Edwards Limestone Formation of central Texas, a distance over 200 miles away.

The most comprehensive analysis of Paleo-Indian movements, as defined by the distance of raw materials from sources, is that by Hester and Grady (1977) who attempted to reconstruct "band territory" sizes using such data. They used raw material data from Blackwater Draw Locality No. 1. Jones-Miller, the Jurgens site and the O1son-Chubbock site and computed airline mile distances to known quarry sources. Based on these measurements, they found that a distance of 90 to 120 miles would be a reasonable radius for a band "territory." In some cases, evidence was found of material moving between 200 and 400 miles, a pattern they believe would reflect specialist procurement or trade with another band (Hester and Grady 1977: 92).

Assuming that the presence of exotic lithic raw materials on these sites is truly a by-product of wide ranging movements of human groups, then impressive evidence has been adduced for mobility among PaleoIndian groups. While most archeologists would accept that some or a11 of these distributions are referrable to mobility, the question of alternative mechanisms needs to be considered. In the Paleo-Indian 
literature, distributions that exceed 200 or more miles are frequently cited as likely examples of expeditions by individuals or task groups or trade with neighboring bands (see Fitting et al. 1966: 128; Wilmsen and Roberts 1978: 179; Wheat 1971: 27; Hester and Grady 1977: 92).

The question of procurement by direct expeditions or movement of artifacts by trade or exchange are not processes that can be directly examined using archeological means. There simply are no archeological correlates of either (cf. Webb 1974: 360). To evaluate for these possibilities, we must turn to the ethnographic records of hunter-gatherers.

Binford (n.d.) has recently criticized the traditional interpretation that the presence of exotic materials on an archeological site indicates evidence of a trip made from that location to the source. Frequently attendant to this view is the inference that the farther a material has come, the greater its value. Based on his ethnoarchaeological fieldwork, Binford (n.d.) has created an alternative model to account for the widespread distribution of exotic raw materials in hunter-gatherer settlement systems that does not require a strategy of direct procurement. From observing the Nunamiut Eskimo and the Alyawara of Australia, he noted that the gathering of raw materials of all types was accomplished as an activity "embedded" in other more primary subsistence activities taking place in a locality. As these groups move seasonally to different localities, they gather resources including lithic raw materials native to a particular locale. No special trips are made for raw materials except in cases of rare emergency. As tools manufactured from raw material native to one region are curated by transport, some naturally end up as exotic items in other localities. Thus, Binford (n.d.) argues that among mobile hunter-gatherers, procurement is at "...the 'scale' of 
the habitat exploited from the location..." of a camp. The archeological implications of Binford's model should be obvious. Those artifacts suspected to be exotic to a locality should be represented primarily by finished artifacts and lithic debitage related to maintenance or recycling.

The idea of a trading system where a group of people living in one region supply raw material or tools to a group living in another region is a "logical" notion that has no basis in hunter-gatherer literature. Nor is there any evidence that such groups claim territories or claim the natural resources of regions (Lee and Devore 1968: 8-9). A high degree of fluidity of personal or demographic flux has been repeatedly observed for modern hunter-gatherers, movements which seem to promote maximum accessibility of people to resources (Yellen and Harpending 1972; Ye11en 1977).

The circulation or movement of artifacts by means of gift giving or exchange is a common activity among hunter-gatherers, one that was probably common in prehistory as well. Gift giving is nearly constant among local groups and frequently takes place when individuals or groups visit or move in with other nearby groups. Where exchange takes place within the local group, those items should form archeological assemblages that have no relevance to inter-regional and interband exchange. Where exchange takes place between local groups, it is a direct by-product of movement. The few recorded examples of long distance interband exchange, such as the Queensland axe exchange which was 400 miles in width (Sahlins 1972: 281-282), are interesting for they involved finished items--not assemblages, items with lifespans that would certainly exceed that of chipped stone implements. Many of the exotic artifacts in Paleo-Indian sites represent entire assemblages or tool kits, not just occasional items. 
For these reasons, then, I believe most of the exotic lithic remains among Paleo-Indian sites represent by-products of mobility. The weakest part of this argument is that little or none of the lithic materials have been rigorously tied to sources using physical methods such as neutron activation (see Luedtke 1979). Physico-chemical studies may indicate that some of the sources for exotics are not as distant as thought. I would predict, however, that the pattern of 1 ong distance importation of lithic materials will basically hold because the trend can be observed at the continental level. Practically all Paleo-Indian sites, not just the ones in the Northeast, exhibit the presence of exotics. The Paleo-Indian pattern contrasts markedly with the following Archaic stage raw material patterns which reflect increasing reliance on local and more coarse grained raw materials. This, I would also argue, is a by-product of decreasing mobility and habitat size, a result of increasing population.

\section{The Flaking Qualities of Cryptocrystalizne Materials}

Probably the most obvious and acceptable part of the argument presented here concerns the desirable qualities of fine-grained materials for knapping. The combined work of Crabtree $(1967,1972)$ and many of the people he has trained or influenced has indicated repeatedly that the significant variation in flaking properties exists within rocks that fracture conchoidally. Those materials easiest to shape especially for flat surfaces, even edges, and acute angles are those such as quartz crystal, chalcedony, jasper, agate, chert, hornstone, and some of the fine-grained igneous rocks (see Crabtree 1967). These rocks all share in common the properties of brittleness and isotrophism, both necessary ingredients for controlled reduction. The anomalous exception to this 
list of materials is obsidian which surprisingly was not used that much by Paleo-Indian groups. When asked why Paleo-Indians tended to ignore obsidian, Crabtree (personal communication, 1972) indicated that they wanted tough siliceous materials for their tools. Obsidian, the ultimate in workability hence "plasticity," may be too brittle, thus to unreliable for the cutting, scraping and piercing functions of these tool kits. In this connection, heat treating of cherts in a mobility strategy is likely valued more for the increase in workability or "plasticity" it provides than simply for allowing sharper edges to be created. This may be the case since thermal alterations tend to weaken the edge strengths of some silicates (see Rick 1978) causing tool edges to dull faster. More work in general could be profitably done using instruments from physics and engineering to study brittleness, levels of material failure and so forth to evaluate how groups were manipulating these properties. Evidence of Maintenance and Recycling

Up to this point in this research, I have not systematically gone through the Paleo-Indian literature and identified the full range or resharpening and recycling strategies, although I can say that evidences of both are abundant. A major pattern in resharpening of blade and tip edges can be seen on the fluted point and Plano forms over North America. For these forms, rejuvenation seems to concentrate on the tip area rather than the lateral margins of the blade. This seems to be a conscious effort to maintain a constant blade width during reduction in blade length. This contrasts tremendously with Dalton and many Early Archaic point resharpening strategies which focus on blade margin reduction. Many of the tapered and probably hafted end-scrapers show marked variation in length, a result no doubt of resharpening. It is my feeling that all 
of this is ultimately quantifiable, and when that is done, we can begin to have an objective measure of lifespan.

As might be expected, evidence of recycling is quite variable across the many assemblages throughout the country. No one tool form always goes into another form. At the Debert site, for example, several endscrapers were recycled into bipolar cores (MacDonald 1968). In some assemblages, points are transformed into endscrapers (e.g., Goodyear 1974). One of the best studies of this sort is the work of Judge (1973) who analyzed the various recycling strategies of the Folsom preform. Conclusions

There is much work yet to be done in evaluating the hypothesis that among mobize hunter-gatherers, the use of cryptocrystazine raw materials is a strategy for creating portable and flexible technologies to offset geographic incongruences between resources and consumers. There are many interesting implications of this hypothesis that have not been dealt with here. Some of these include an ability to detect mobility among low density populations based on the presence of cryptocrystalline and the role of tool design determining raw material selection. 


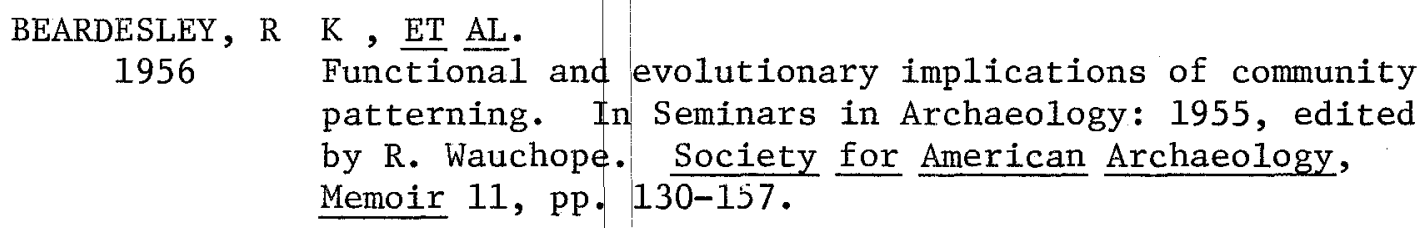

HESTER, JAMES J. AND JAMES GRADY

Paleo-Indian spcial patterns on the Llano Estacado. In Paleo-Indian Lifeways. The Museum Journal, edited by Eileen Johnson, pp. 78-96. Lubbock.

JUDGE, W. JAMES in New Mexico. University of New Mexico Press, Albuquerque. 


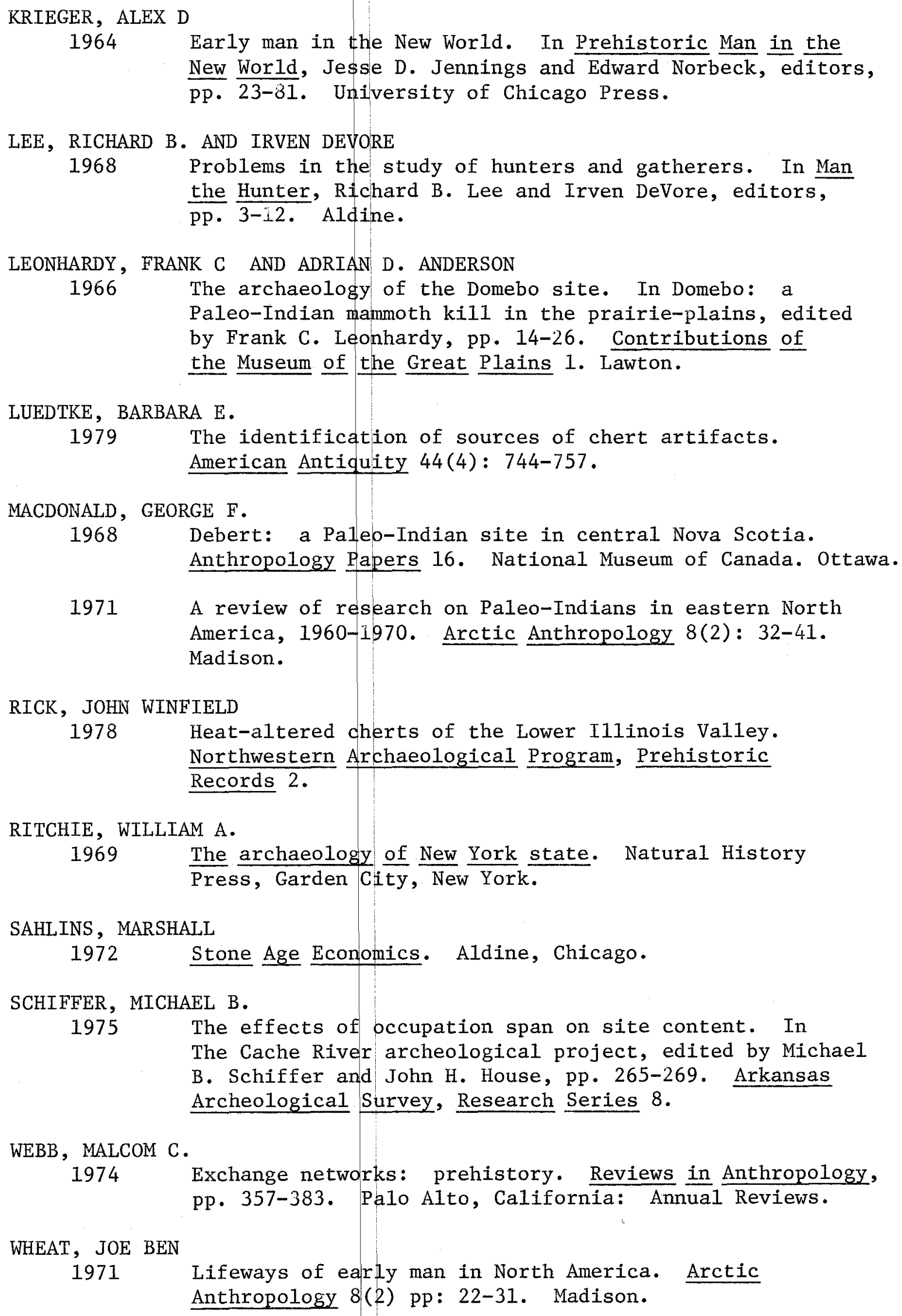


WILLEY, GORDON R.

1966 An introduction to American archaeology 1 North and Middle America. Prentice-Hall, Inc. Englewood cliffs, New Jersey.

WILMSEN, EDWIN N.

1970 Lithic analysis and cultural inference: a Paleo-

Indian case. Anthropological Papers of the University of Arizona 6. Tucson.

WILMSEN, EDWIN N. AND FRANK H. H. ROBERTS, JR.

1978 Lindenmeier, 1934-1974. Smithsonian Contributions

to Anthropology 24.

WITTHOFT, JOHN

1952

A Paleo-Indian site in eastern Pennsylvania: an early

hunting culture. American Philosophical Society

Proceedings 96: $464-495$.

WORMINGTON, H. M.

1957

Ancient man in North America, 4th Edition. Denver

Museum of Natural History. Popular Series 4. Denver.

YELLEN, JOHN E.

1977 Archaeological Approaches to the Present. Academic Press.

YELLEN, JOHN E. AND HENRY HARPENDING

1972 Hunter-gatherer population and archeological inference.

Wor1d Archaeology 4: 244-253. 